\title{
Corrigendum
}

\section{The myeloproliferative neoplasms, unclassifiable: clinical and pathological considerations}

Umberto Gianelli, Daniele Cattaneo, Anna Bossi, Ivan Cortinovis, Leonardo Boiocchi, Yen-Chun Liu, Claudia Augello, Arturo Bonometti, Stefano Fiori, Nicola Orofino, Francesca Guidotti, Attilio Orazi and Alessandra Iurlo

Modern Pathology (2017) 30, 1043; doi:10.1038/modpathol.2017.2

Correction to: Modern Pathology advance online publication 14 October 2016; doi: $10.1038 / \mathrm{mod}$ pathol.2016.182

In this article, on page 6, left column, in the 'Discrepancies between Morphological Profiles and
Clinical Features' section, second paragraph, line 6 should read '.... but 13 patients out of 25 did not meet at least two of the four minor diagnostic criteria defined in the updated WHO 2008 classification for primary myelofibrosis...' 